\title{
THE INTRA-CHROMOSOMAL MAPPING OF THE NORIN 10 AND TOM THUMB DWARFING GENES
}

\author{
JAMES A. McVITTIE, MICHAEL D. GALE, GERALDINE A. MARSHALL \\ and BRIAN WESTCOTT \\ Plant Breeding Institute, Trumpington, Cambridge
}

Received 29.iv.77

\begin{abstract}
SUMmary
The major genes for dwarfism in Norin 10 wheat, Rht 1 and $R h t 2$ are located on chromosomes 4A and 4D. The gene for extreme dwarfness from Tom Thumb, Rht 3 , is located close to, or is allelic with Rht 1 on chromosome $4 \mathrm{~A}$. An $\mathrm{F}_{2}$ telocentric mapping technique has been employed to locate these genes by using their gibberellin insensitive phenotype. Gai/Rht 1 and Gai/Rht 3 were estimated to be 13 map units from the centromere on the $\alpha$ arm of chromosome 4A and Gai/Rht 215 map units from the centromere on the long arm of chromosome 4D. These results suggest that the genes are part of a homoeoallelic series.
\end{abstract}

\section{INTRODUCTION}

DURING the past 30 years wheat breeders have endeavoured to produce short stiff-strawed varieties that are compatible with heavy applications of nitrogenous fertiliser as used in present day agriculture. The most successful genetic source of short straw has been the Japanese variety Norin 10 . Another source of extreme dwarfism, is Tom Thumb. This variety has, as yet, been less widely used in the production of commercial dwarfs.

Norin 10 carries two major genes for short straw (Allan and Vogel, 1968). Dwarfism in Tom Thumb is controlled by a single gene carried on chromosome 4A (Morris, Schmidt and Johnson, 1972). These genes are known as Rht 1, Rht 2 and Rht 3 respectively.

The dwarfing genes from both Norin 10 and Tom Thumb are associated with abnormal hormone metabolism and high endogenous levels of gibberellin (Radley, 1970; Gale and Marshall, 1973) and may be identified by an insensitivity of aerial plant parts to exogenously applied gibberellic acid. This GA-insensitivity and the dwarf phenotypes have been described as being controlled by pairs of linked loci, e.g. Rht 2 linked to Gai 2 and Rht 3 to Gai $3(\mathrm{Hu}, 1974)$. Observations of $\mathrm{F}_{2}$ 's and $\mathrm{F}_{3}$ 's from crosses in which Rht 3/rht 3 and Gai 3/gai 3, and Rht 2/rht 2 and Gai 2/gai 2 segregated have, however, revealed no recombination between the two phenotypes. In these experiments (Gale, unpublished) the 95 per cent upper confidence limits for recombination were 1.2 per cent and 2.5 per cent respectively. Also, the relative potencies of the three pairs of phenotypes, i.e. in degree of height reduction, Rht $3>$ Rht $2>R h t 1$, and in degree of GA-insensitivity, Gai 3>Gai 2> Gai 1, suggest that, in each case, both phenotypes are the expression of a single gene. While observations of this type can never prove the pleiotropic relationship between dwarfism and the reduced response to GA, they favour such an explanation. Both symbols are retained in a combined form below, e.g. GailRht 1 .

Monosomic analysis of the GA-insensitive phenotype of the semi- 
dwarfing genes has facilitated the chromosomal location of Gai/Rht 1 on chromosome 4A (Gale and Marshall, 1976), Gai/Rht 2 on chromosome 4D (Gale, Law and Worland, 1975) and Gai/Rht 3 also on 4A (Gale, Law, Marshall and Worland, 1975), thus confirming the location of Rht 3 (Morris et al., loc. cit.). Observations of families segregating for both Gai/Rht 1 and Gai/Rht 3 showed no recombination between the two genes for GAinsensitivity with an upper 95 per cent confidence limit of 0.7 per cent (Gale and Marshall, 1976). These results indicate that these genes are either extremely tightly linked or are alternative alleles at the same locus on chromosome $4 \mathrm{~A}$.

This paper describes telocentric mapping experiments to locate the dwarfing genes relative to the centromeres of chromosomes $4 \mathrm{~A}$ and $4 \mathrm{D}$.

\section{MAterials AND METhods}

The sources of Gai/Rht 2 and Gai/Rht 3 used were Sd2 and Tom Thumb respectively. Sd2 (Gaines sib. 2), kindly supplied by Dr R. E. Allan of Washington State University, was hybridised with the Chinese Spring ditelocentrics (42tt, i.e. 42 chromosomes including two telocentrics) for the long and short arms of chromosome 4D, i.e. CSDT4DL and GSDT4DS. Tom Thumb was hybridised with CSDT4A $\alpha$ and Chinese Spring monotelodisomic $4 \mathrm{~A} \beta$. The $\beta$ arm of chromosome $4 \mathrm{~A}$ is maintained as a heteromorph because $\mathrm{CSDT} 4 \mathrm{~A} \beta$ is sterile.

In each case the initial cross was made with the aneuploid as the female parent. $\mathrm{F}_{2}$ grain was collected from several $42 \mathrm{t}$ plants selected from the $\mathrm{F}_{1}$ 's for each cross. $\mathrm{F}_{2}$ grain was germinated on moist filter paper and, after removal of root tips for subsequent cytological examination, the seedlings were transplanted into vermiculite. After 10 days at $18 / 15^{\circ} \mathrm{C}$ for $20 / 4$ hours and daily applications of culture solution containing 10 parts $/ 10^{6}$ gibberellic acid (Berelex, Plant Protection Ltd.), the seedlings were scored for their reaction to GA. Under these conditions it is possible to distinguish three phenotypes, i.e. fully and partially insensitive to gibberellin and responsive to gibberellin.

The $\mathrm{F}_{2}$ method of telocentric mapping was used in preference to a backcross method since for genes such as Gai/Rht that can be fully classified, i.e. the heterozygote may be distinguished from both homozygotes, the former method is always more efficient (Westcott, Gale and McVittie, 1978).

\section{Results AND Discussion}

For both genes, the phenotype of the heterozygote, Gai/Rht, gai/rht, is indistinguishable from that of the hemizygote, Gai/Rht.

Therefore only observation of recombination between the gene and the centromere can identify the critical arm. An initial experiment in which 20 seedlings from each cross were examined revealed recombination only on the $\alpha$ arm of chromosome 4A and the short arm of 4D.

The results of a more detailed examination of these arms are given in table 1 .

The maximum likelihood estimates of $x$, the transmission of the telocentrics through the female, $y$, the transmission of the telocentrics through the male, and $p$, the recombination frequencies between the genes and the 
TABLE 1

Results of F2 seedling GA-insensitivity tests of the crosses CSDT4A $\times$ Tom Thumb and CSDTADS $\times S d 2$. Plants scored as having 41 and 43 chromosomes are omitted from the table

\begin{tabular}{|c|c|c|c|c|}
\hline \multirow[b]{2}{*}{ Chromosome arm } & \multirow[b]{2}{*}{ Genotypic classification } & \multicolumn{3}{|c|}{ Chromosome complemen } \\
\hline & & 42 & $42 t$ & $42 \mathrm{tt}$ \\
\hline \multirow[t]{3}{*}{$4 \mathrm{~A} \alpha$} & Gai/Rht 3, Gai/Rht 3 & 20 & 4 & 0 \\
\hline & Gai/Rht 3, gai/rht 3 & 7 & 25 & 0 \\
\hline & gai/rht 3, gai/rht 3 & 1 & 5 & 3 \\
\hline \multirow[t]{3}{*}{$4 \mathrm{DS}$} & Gai/Rht 2, Gai/Rht 2 & 21 & 4 & 0 \\
\hline & Gai/Rht 2, gai/rht 2 & 8 & 26 & 1 \\
\hline & gai/rht 2, gai/rht 2 & 0 & 5 & 7 \\
\hline
\end{tabular}

centromeres are given in table 2. The observation that transmission of the telocentric through the female is normal allows $y$ and $p$ to be more precisely estimated assuming the female transmission to be $0 \cdot 5$.

In both cases the male transmission rate is low, consequently reduced viability of the ditelocentric zygotes relative to that of the other two classes could only be detected in much larger populations than those tested. Even if it existed, such differential viability could only have a minimal deleterious effect on the precision of the estimate of $p$ (Westcott et al., loc. cit.).

\section{TABLE 2}

Telocentric transmissions for the critical chromosome arms and gene-centromere recombination frequencies for the dwarfing loci. Standard errors are given after each estimate

$\begin{array}{ccccc}\text { Gene } & \begin{array}{c}\text { Critical } \\ \text { chromosome } \\ \text { arm }\end{array} & \overbrace{x}^{\text {Telocentric transmission }} & y & \begin{array}{c}\text { Gene-centromere } \\ \text { recombination } \\ p\end{array} \\ \text { Gai/Rht } 3 & \text { 4A } \alpha & 0.528(0.736) & 0.096(0.052) & 0.150(0.034) \\ \text { Gai/Rht } 2 & \text { 4DS } & 0.474(0.120) & 0.216(0.068) & 0.133(0.031)\end{array}$

Since Gai/Rht 1 and Gai/Rht 3 are carried at close or identical loci, these experiments also locate the weaker gene from Norin 10 about 15 map units from the centromere on $4 \mathrm{~A} \alpha$.

The marked similarity of the gene-centromere recombination frequencies for the two loci suggests that they form part of a homoeallelic series within the group 4 chromosomes. The assumption that $4 \mathrm{~A} \alpha$ and $4 \mathrm{DS}$ are homoeologous is in agreement with the results of Hart (1973) who found that $4 \mathrm{~A} \alpha, 4 \mathrm{BL}$ and $4 \mathrm{DS}$ display homoeologous functions with regard to the control of alcohol dehydrogenase isoenzymes.

This result raises the question of a further Gai/Rht locus on $4 \mathrm{BL}$. It seems likely that the group 4 chromosomes have, during the evolution of hexaploid bread wheat, undergone considerable structural change. This is shown by the apparent inability of the homoeologues to compensate for each other (Sears, 1966) and by the lack of agreement between their karyotypic and genetic homoeology. Nevertheless, unless the alcohol dehydrogenase loci are very distant from the Gai/Rht loci it is likely that the 4BL locus carrying a gai/rht allele still exists. Variation at this locus has not been found although a wide range of hexaploid dwarfs have been screened 
for GA-insensitivity. Nevertheless, in view of the agronomic importance of the three alleles known at present, it may be profitable to attempt to induce dwarf mutation at this locus. Experiments of this kind, which are already in progress, should be facilitated by the partial dominance of the GA-insensitive phenotype which will make screening possible among M2 seedlings.

The intra-chromosomal locations of the known Gai/Rht genes will facilitate the directed manipulation of these alleles either singly or together by standard aneuploid techniques. These results also provide dominant major genes on chromosome arms which, until now, have been void of easily handled genetic markers.

Acknowledgment.--The senior author gratefully acknowledges the award of a Department of Agriculture and Fisheries for Scotland Postgraduate studentship.

\section{REFERENCES}

ALLAN, R. E., AND VOGEL, O. A. 1968. A method for predicting semi-dwarf genotypes in Triticum aestivum L. Agronomy Abstracts, p.2.

GALE, M. D., AND MARShall, G. A. 1973. Insensitivity to gibberellin in dwarf wheats. Annals of Botany, 37, 729-735.

Gale, M. D., ANd marshall, G. A. 1976. The chromosomal location of Gai 1 and Rht 1 , genes for gibberellin insensitivity and semi-dwarfism, in a derivative of Norin 10 wheat. Heredity, 37, 283-289.

Gale, M. D., LAW, C. N., Marshall, G. A., AND WORLand, A. J. 1975. The genetic control of gibberellic acid insensitivity and coleoptile length in a "dwarf" wheat. Heredity, 34, 393-399.

GALE, M. D., LAW, C. N., AND WORLAND, A. J. 1975. The chromosomal location of a major dwarfing gene from Norin 10 in new British semi-dwarf wheats. Heredity, 35(3), 417-421.

HART, G. 1973. Homoeologous gene evolution in hexaploid wheat. Proceedings of the 4th International Wheat Genetics Symposium, Columbia, Missouri, 805-810.

нU, м. L. 1974. Genetic analyses of semi-dwarfing and insensitivity to gibberellin $\mathrm{GA}_{3}$ in hexaploid wheat (Triticum aestivum L. em Thell.) PhD Thesis, Washington State University, Department of Agronomy and soils.

MORRIS, R., SCHMIDT, J. W., AND JOHNSON, v. A. 1972. Chromosomal location of a dwarfing gene in "Tom Thumb" wheat derivative by monosomic analysis. Crop Science, 12, 247-249.

RADLEY, M. 1970. Comparison of endogenous gibberellins and response to applied gibberellin of some dwarf and tall wheat cultivars. Planta, 92, 292-300.

SEARS, E. R. 1966. Nullisomic-tetrasomic combinations in hexaploid wheat. In Chromosome Manipulation and Plant Genetics, ed. R. Riley, and K. R. Lewis, pp. 29-45. Oliver \& Boyd, Edinburgh.

WESTCOTT, B., GALE, M. D., AND MCVITTIE, J. A. 1978. A comparison of backcross and selfing. Methods for telocentric chromosome mapping in wheat. Heredity, 40, 59-66. 